\title{
Correction: Assessing the effects of mining projects on child health in sub-Saharan Africa: a multi-country analysis
}

Hermínio Cossa ${ }^{1,2,3^{*}}$, Dominik Dietler ${ }^{1,2}$, Eusébio Macete ${ }^{3,4}$, Khátia Munguambe ${ }^{3,5}$, Mirko S. Winkler ${ }^{1,2}$ and Günther Fink ${ }^{1,2}$

\section{Correction: Global Health 18, 7 (2022)}

https://doi.org/10.1186/s12992-022-00797-6

Following publication of the original article [1], the authors flagged that the article had published with a duplicate of Fig. 4 in place of Fig. 5.

Figure 5 has now been corrected in the published article and may be found in this erratum.

\section{Author details}

${ }^{1}$ Swiss Tropical and Public Health Institute, Kreuzstrasse 2, 4123 Allschwil, Switzerland. ${ }^{2}$ University of Basel, P.O. Box, CH-4003, Basel, Switzerland. ${ }^{3}$ Manhiça Health Research Centre, 1929 Maputo, Mozambique. ${ }^{4}$ National Directorate of Public Health, Ministry of Health, 264 Maputo, Mozambique. ${ }^{5}$ Faculty of Medicine, University Eduardo Mondlane, 3453 Maputo, Mozambique.

Published online: 22 February 2022

\section{Reference}

1. Cossa, et al. Assessing the effects of mining projects on child health in sub-Saharan Africa: a multi-country analysis. Global Health. 2022;18:7. https://doi.org/10.1186/s12992-022-00797-6.

The original article can be found online at https://doi.org/10.1186/s12992022-00797-6.

*Correspondence: herminio.cossa@manhica.net

${ }^{3}$ Manhiça Health Research Centre, 1929 Maputo, Mozambique

Full list of author information is available at the end of the article original author(s) and the source, provide a link to the Creative Commons licence, and indicate if changes were made. The images or other third party material in this article are included in the article's Creative Commons licence, unless indicated otherwise in a credit line to the material. If material is not included in the article's Creative Commons licence and your intended use is not permitted by statutory regulation or exceeds the permitted use, you will need to obtain permission directly from the copyright holder. To view a copy of this licence, visit http://creativecommons.org/licenses/by/4.0/. The Creative Commons Public Domain Dedication waiver (http://creativeco mmons.org/publicdomain/zero/1.0/) applies to the data made available in this article, unless otherwise stated in a credit line to the data. 

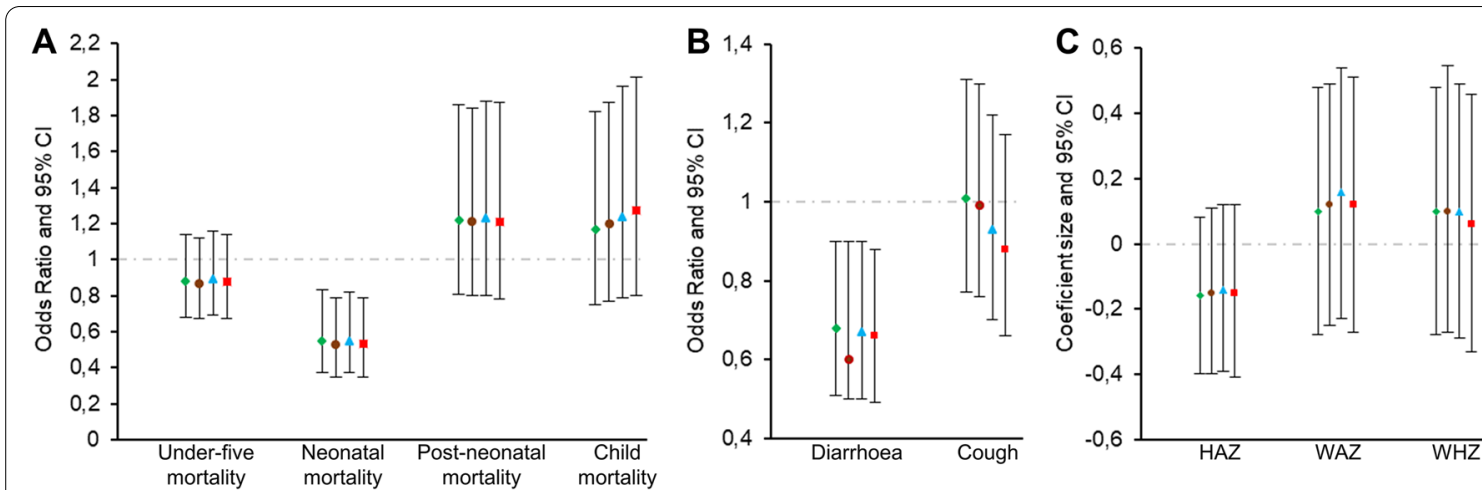

Drop $10-15 \mathrm{~km}$

Drop $10-20 \mathrm{~km}$

Drop 10-25km

0-10km Baseline

Fig. 5 Sensitivity analysis of all child health indicators using logistic (mortality and morbidities) and linear (anthropometrics) regression models. Estimates are adjusted Odds Ratios of under-five and age-specific mortality rates (A) and child morbidities (B) and adjusted beta coefficients of child anthropometrics (C). The baseline specification model (control group is the entire 10-50 km area) is included for comparison. Error bars show $95 \%$ confidence intervals clustered at the survey-cluster level. bef - before; yrs. - years 